\title{
The use of fenugreek supplementation in diabetes
}

\author{
Aamir Jalal Al Mosawi* \\ Advisor Doctor, Baghdad Medical City and the Iraqi Ministry of Health, Baghdad, Iraq
}

Received: 30 July, 2021

Accepted: 09 August, 2021

Published: 10 August, 2021

*Corresponding author: Aamir Jalal Al Mosawi, Advisor Doctor, Baghdad Medical City and the Iraqi Ministry of Health, Baghdad, Iraq,

E-mail: almosawiAJ@yahoo.com

Keywords: Fenugreek; Diabetes; Research findings https://www.peertechzpublications.com

Advisor Doctor, Baghdad Medical City and the Iraqi Ministry of Heath, Baghdad, Iraq

Check for updates

\section{Abstract}

Dietary health supplements have increasingly used in the prevention and treatment of chronic disorders. During the previous decades, fenugreek (Trigonella foenumgraecum) seeds have been reported to have hypoglycemic and cholesterol lowering effects when used in type 1 and type 2 diabetes mellitus patients, and in experimental diabetic animals. The aim of this paper is to review fenugreek research findings relevant to its use in diabetes.

There is convincing research evidence suggesting that fenugreek can improve hyperglycemia and has a protective effective against diabetic complications through immunomodulatory, insulin stimulation, and antioxidant effects, enhancing adipocyte differentiation, inhibition of inflammation in adipose tissues, and preventing or lessening pancreatic and renal damage. Many of the beneficial effects of fenugreek in diabetes have been attributed to four bioactive components including diosgenin, 4-hydroxyisoleucine, furostanolic saponins, and the fiber in fenugreek.

During the 1970 s and 1980s, several experimental researches on rats and dogs suggested that fenugreek (Trigonella foenum graecum seeds) has a hypoglycemic effect [1-4].

The work of Madar, et al. (1988) suggested that fenugreek have the potential to be used in the treatment of non-insulin dependent diabetics, as they reported that the use of powdered fenugreek seed in a dose of $15 \mathrm{~g}$ soaked in water was associated with a marked decrease in the postprandial glucose levels [5].

Sharma and colleagues (1990) reported that the use of defatted fenugreek seed powder in the treatment of in type I diabetes, in a dose of $100 \mathrm{~g}$ divided in two doses for ten days, was associated with a considerable lowering of fasting blood sugar and resulted in an improvement in the glucose tolerance test. They also found a 54\% lowering of 24-hour urinary glucose excretion. Treatment also had an important lowering effect on serum total cholesterol, LDL and VLDL cholesterol and triglycerides were also significantly reduced [6].

Khosla and colleagues (1995) reported an experimental study on rats which showed that oral fenugreek ( 2 and $8 \mathrm{~g} /$ $\mathrm{kg}$ dose) was associated with a considerable lowering $(\mathrm{P}<$ 0.05) in blood glucose in normal and diabetic rats, and the hypoglycemic effect in this study was dose related [7].

Sauvaire, et al. (1998) reported that 4-hydroxyisoleucine which is an amino acid extracted and purified from fenugreek seeds has an insulinotropic effect. 4-Hydroxyisoleucine augments glucose-induced insulin secretion from islets of Langerhans from rats and humans [8].

The experimental work of Broca, et al. (1998) on rats suggested that the antidiabetic effects of 4-hydroxyisoleucine on rats with non-insulin dependent diabetes result is partly attributed to a direct stimulation of the pancreatic B cell. They found that in non-insulin-dependent diabetic rats, a single intravenous administration of 4-hydroxyisoleucine in a dose of $50 \mathrm{mg} / \mathrm{kg}$ restored to some extent glucose-induced insulin response without affecting glucose tolerance. They also found that the subchronic intake of 4-hydroxyisoleucine. $50 \mathrm{mg} / \mathrm{kg}$, daily lowered basal hyperglycemia, reduced basal insulinemia, and, improved glucose tolerance [9].

The experimental work of Raju, et al. (2001) on alloxan diabetic rats showed that fenugreek seed powder improves glucose homeostasis in tissues by reversing the abnormal glycolytic, gluconeogenic and lipogenic enzymes [10].

The experimental work of Anuradha and Ravikumar (2001) on rats showed that diabetic rats experience an increased lipid peroxidation and a higher susceptibility to oxidative stress associated with depletion of antioxidants in liver, kidney and pancreas. They reported that treatment with fenugreek seed powder normalized the antioxidant status [11]. 
Gupta, et al. (2001) reported a study which included 25 new cases of type 2 diabetes who had fasting glucose less $200 \mathrm{mg} /$ $\mathrm{dl}$. They treated twelve patients with hydro-alcoholic extract of fenugreek seeds $1 \mathrm{gm}$ daily, and thirteen patients were treated with dietary control, exercise and placebo capsules for two months. The study showed that the addition of fenugreek seeds was associated with improved glycemic control and reduced insulin resistance in mild type- 2 diabetic patients, and had a favorable effect on hypertriglyceridemia [12].

Puri and colleagues (2002) reported an experimental study on sub-diabetic and mild diabetic rabbits treated with fenugreek seeds in a dose of $50 \mathrm{mg} / \mathrm{kg}$ body weight for 15 days. Treatment was associated with a considerable lessening of the glucose tolerance curve and improvement in the glucose induced insulin response.

Puri and colleagues attributed the hypoglycemic effect to stimulation of insulin synthesis and/or secretion from the beta pancreatic cells of Langerhans.

Puri and colleagues also reported that treatment of five severely diabetic rabbits markedly reduced fasting blood glucose, but the reduction was not much correlated with the elevation of fasting serum insulin level, suggesting an extrapancreatic effect [13].

The experimental work of Thakran, et al. (2004) alloxan diabetic rats suggested that treatment with fenugreek seed powder can reverse the diabetic state at the cellular level, help with the metabolic normalization, has a protective effect against the development of liver degenerative and nephropathic changes in diabetic rats [14].

Xue, et al. (2007) reported an experimental study on streptozotocin-induced diabetic rats which showed that fenugreek can reduce blood glucose, kidney /body weight ratio, blood lipids, and improve hemorheological properties when treatment repeated for six weeks [15].

$\mathrm{Lu}$, et al. (2007) reported a clinical study which included sixty-nine patients with type 2 diabetes mellitus whose blood glucose levels were not adequately controlled by oral sulfonylureas hypoglycemic treatment. Forty six patients received fenugreek and 23 patients received placebo for 12 weeks. The addition of fenugreek to sulfonylureas hypoglycemic treatment was associated with reduction of blood glucose level and improved symptoms [16].

Kassaian, et al. (2009) reported the treatment of eighteen diabetic patients with fenugreek seeds powder10 grams daily. Eleven patients took fenugreek mixed in hot water and seven took it mixed with yoghurt for eight weeks. Fasting blood sugar, triglycerides, and VLDL-C were considerably (25\%, $30 \%$ and $30.6 \%$ respectively) only in patients who took fenugreek seed soaked in hot water [17].

Mowla, et al. (2009) reported an experimental study on alloxan-induced diabetic rats showed that treatment with fenugreek) seed extract $1 \mathrm{~g} / \mathrm{kg}$ /body weight has an effective hypoglycemic effect, and a high dose of $3 \mathrm{~g} / \mathrm{kg} /$ body weight was not associated with any toxicity [18].
Hamden, et al. (2010) reported and experimental study on rats with alloxan-induced diabetes who had pancreatic islet and beta-cells damage, low activities of superoxide dismutase, glutathione peroxidase, catalase, and reduced glutathione content in kidney.

Treatment with fenugreek oil was associated with marked improvement in blood glucose levels, glucose intolerance, and insulin sensitivity occurring in association with improvement in pancreatic and renal damage, and reduction of raised levels of lipid peroxidation, creatinine, albumin, and urea. The beneficial effects of fenugreek in this study were attributed to immunomodulatory, insulin stimulation and antioxidant effects [19].

Uemura $\mathrm{T}$, et al (2010) reported and experimental study on diabetic obese KK-Ay mice which showed that fenugreek can improve diabetes by enhancing adipocyte differentiation and inhibiting inflammation in adipose tissues through the effects of diosgenin which is an aglycone [20].

Xue, et al. (2011) reported an experimental on rats with streptozotocin induced diabetic nephropathy who had reduced activities of superoxide dismutase and catalase, elevated levels of malondialdehyde in the serum and kidney, and elevated levels of 8-hydroxy-2-deoxyguanosine in renal cortex DNA and urine. Treatment with fenugreek restored these abnormalities in a dose-dependent manner. Treatment considerably improved all of the ultramorphological renal changes, including the uneven thickening of the glomerular base membrane. This experimental study showed that fenugreek has a protective effect against functional and morphological renal damage in diabetic rats mediated through enhancing antioxidants and inhibition of buildup of oxidized DNA in the kidney [21].

Puri and colleagues (2012) reported and experimental study on rabbits with alloxan-induced diabetes which showed that a compound GII purified from the water extract of fenugreek had an antidiabetic property [22].

Hamza, et al. (2012) reported an experimental study on mice which showed that fenugreek had a preventive and curative effect in type 2 diabetes induced by high-fat diet [23].

Gupta, et al. (2014) reported an experimental study on streptozotocin-induced diabetic rats that had marked increase in the expressions of retinal inflammatory tumor necrosis factor $-\alpha$ and interleukin- $1 \beta$ and angiogenic vascular endothelial growth factor and protein kinase $C-\beta$ molecular biomarkers. The study showed that treatment with fenugreek 100 and $200 \mathrm{mg} / \mathrm{kg}$ body weight for 24 weeks was associated with significant inhibition in the expression of the elevated inflammatory and angiogenic molecular biomarkers. Fenugreek also had a positive modulatory effect on retinal oxidative stress, and prevented the development of retinal vascular leakage. This study suggested that fenugreek supplementation can help in preventing diabetes-induced retinal degeneration [24].

Neelakantan, et al. (2014) conducted a meta-analysis which included ten clinical trials and showed that fenugreek seeds had beneficial effects on glycemic control in diabetic patients [25]. 
Smith, et al. (2014) reviewed the research findings relevant to the use of dietary supplements lowering blood glucose, and found that the strongest research evidence was associated with alpha-lipoic acid and fenugreek [26].

Rawat, et al. (2014) reported an experimental study on high-fructose diet fed streptozotocin-induced diabetic rats which showed that 4-Hydroxyisoleucine isolated from fenugreek seeds improved insulin resistance by promoting mitochondrial biogenesis and acting through AMPK and Akt dependent pathway [27].

Gaddam, et al. (2015) reported a 3-year randomized, controlled, parallel clinical study which included pre-diabetic individuals. Sixty-six individuals were treated with fenugreek powder, $5 \mathrm{~g}$ twice a day before meals, and seventy-four individuals served as controls. Treatment was associated with considerable lowering of fasting plasma glucose, postprandial plasma glucose, and low density lipoprotein cholesterol, and marked increase in serum insulin. Controls had 4.2 times higher chance of developing diabetes compared to treated individuals. Treatment was not associated with adverse effects and the beneficial effect was attributed to reduction of insulin resistance [28].

Verma, et al. (2016) reported a placebo-controlled clinical study which included 154 patients with type 2 diabetes. 90day treatment with Fenugreek extract, furostanolic saponins (Fenfuro) $500 \mathrm{mg}$ twice daily was associated with marked lowering of fasting plasma and post-prandial blood sugar levels. More than $80 \%$ of the treated patients experienced reductions in fasting plasma sugar levels compared to $62 \%$ of patients who received placebo. $89 \%$ of the treated patients experienced a decrease in post-prandial plasma sugar levels compared to $72 \%$ of patients who received placebo. $48.8 \%$ of the treated patients reported lowering of anti-diabetic therapy dosage, while $18.05 \%$ of the patients who received placebo reported lowering of anti-diabetic therapy dosage. Treatment was not associated with adverse effects [29].

Geberemeskel, et al. (2019) reported a study which included 114 newly diagnosed uncomplicated type II diabetic patients. 57 patients received $25 \mathrm{~g}$ fenugreek seed powder solution orally twice a day for one month, and 57 patients received metformin. The study showed that fenugreek had marked effects in improving lipid metabolism in type II diabetes without the occurrence of adverse effects [30].

Hadi, et al. (2020) reported an 8-week controlled clinical study which included 50 patients with type 2 diabetes whom were treated with anti-diabetic drugs. The patients received either $5 \mathrm{~g}$ fenugreek seed powder, three times daily or served as control patients. Compared to the control patients, treated patients experienced a considerable lowering of fasting plasma glucose $(\mathrm{p}=0.024)$ [31].

\section{Conclusion}

There is convincing research evidence suggesting that fenugreek can improve hyperglycemia and has a protective effective against diabetic complications through immunomodulatory, insulin stimulation, and antioxidant effects, enhancing adipocyte differentiation, inhibition of inflammation in adipose tissues, and preventing or lessening pancreatic and renal damage. Many of the beneficial effects of fenugreek in diabetes have been attributed to four bioactive components including diosgenin, 4-hydroxyisoleucine, furostanolic saponins, and the fiber in fenugreek.

\section{References}

1. Mishkinsky JS, Goldschmied A, Joseph B, Ahronson Z, Sulman FG (1974) Hypoglycaemic effect of Trigonella foenum graecum and Lupinus termis (leguminosae) seeds and their major alkaloids in alloxan-diabetic and normal rats. Arch Int Pharmacodyn Ther 210: 27-37. Link: https://bit.ly/3jBRXrZ

2. Ghafghazi T, Sheriat HS, Dastmalchi T, Barnett RC (1977) Antagonism of cadmium and alloxan-induced hyperglycemia in rats by Trigonella foenum graecum. Pahlavi Med J 8: 14-25. Link: https://bit.ly/3fJWVSt

3. Ribes G, Sauvaire Y, Baccou JC, Valette G, Chenon D, et al. (1984) Effects of fenugreek seeds on endocrine pancreatic secretions in dogs. Ann Nutr Metab 28: 37-43. Link: https://bit.ly/3fHBn9a

4. Ribes G, Sauvaire Y, Da Costa C, Baccou JC, Loubatieres-Mariani MM (1986) Antidiabetic effects of subfractions from fenugreek seeds in diabetic dogs. Proc Soc Exp Biol Med 182: 159-166. Link: https://bit.ly/3AqZIHY

5. Madar Z, Abel R, Samish S, Arad J (1988) Glucose-lowering effect of fenugreek in non-insulin dependent diabetics. Eur J Clin Nutr 42: 51-54. Link: https://bit.ly/3fKLYQz

6. Sharma RD, Raghuram TC, Rao NS (1990) Effect of fenugreek seeds on blood glucose and serum lipids in type I diabetes. Eur J Clin Nutr 44: 301-306. Link: https://bit.ly/3s36KzF

7. Khosla P, Gupta DD, Nagpal RK (1995) Effect of Trigonella foenum graecum (Fenugreek) on blood glucose in normal and diabetic rats. Indian $\mathrm{J}$ Physio Pharmacol 39: 173-174. Link: https://bit.ly/3xCrYpb

8. Sauvaire Y, Petit P, Broca C, Manteghetti M, Baissac Y, et al. (1998) 4-Hydroxyisoleucine: a novel amino acid potentiator of insulin secretion. Diabetes 47: 206-210. Link: https://bit.ly/3CunAfN

9. Broca C, Gross R, Petit P, Sauvaire Y, Manteghetti M, et al. (1999) 4-Hydroxyisoleucine: experimental evidence of its insulinotropic and antidiabetic properties. Am J Physiol 277: E617- E623. Link: https://bit.ly/3fLpIWO

10. Raju J, Gupta D, Rao AR, Yadava PK, Baquer NZ (2001) Trigonella foenum graecum (fenugreek) seed powder improves glucose homeostasis in alloxan diabetic rat tissues by reversing the altered glycolytic, gluconeogenic and lipogenic enzymes. Mol Cell Biochem 224: 45-51. Link: https://bit.ly/3iyE5ja

11. Anuradha CV, Ravikumar P (2001) Restoration on tissue antioxidants by fenugreek seeds (Trigonella Foenum Graecum) in alloxan-diabetic rats. Indian J Physiol Pharmacol 45: 408-420. Link: https://bit.ly/3fMySSR

12. Gupta A, Gupta R, Lal B (2001) Effect of Trigonella foenum-graecum (fenugreek) seeds on glycaemic control and insulin resistance in type 2 diabetes mellitus: a double blind placebo controlled study. J Assoc Physicians India 49: 1057-1061. Link: https://bit.ly/3fKqi7e

13. Puri D, Prabhu KM, Murthy PS (2002) Mechanism of action of a hypoglycemic principle isolated from fenugreek seeds. Indian J Physiol Pharmacol 46: 457462. Link: https://bit.ly/3s6MBJ5

14. Thakran S, Siddiqui MR, Baquer NZ (2004) Trigonella foenum graecum seed powder protects against histopathological abnormalities in tissues of diabetic rats. Mol Cell Biochem 266: 151-159. Link: https://bit.ly/37Agist

15. Xue WL, Li XS, Zhang J, Liu YH, Wang ZL, et al. (2007) Effect of Trigonella 
foenum-graecum (fenugreek) extract on blood glucose, blood lipid and hemorheological properties in streptozotocin-induced diabetic rats. Asia Pac J Clin Nutr 16: 422-426. Link: https://bit.ly/3CoW43n

16. Lu FR, Shen L, Qin Y, Gao L, Li H, et al. (2008) Clinical observation on trigonella foenum-graecum $L$. total saponins in combination with sulfonylureas in the treatment of type 2 diabetes mellitus. Chin J Integr Med 14: 56-60. Link: https://bit.ly/3xscFQ0

17. Kassaian N, Azadbakht L, Forghani B, Amini M (2009) Effect of fenugreek seeds on blood glucose and lipid profiles in type 2 diabetic patients. Int $\mathrm{J}$ Vitam Nutr Res 79: 34-39. Link: https://bit.ly/3AsiSNA

18. Mowla A, Alauddin M, Rahman MA, Ahmed K (2009) Antihyperglycemic effect of Trigonella foenum-graecum (fenugreek) seed extract in alloxan-induced diabetic rats and its use in diabetes mellitus: a brief qualitative phytochemical and acute toxicity test on the extract. Afr J Tradit Complement Altern Med 6 : 255-261. Link: https://bit.ly/3CvSyUD

19. Hamden K, Masmoudi H, Carreau S, Elfeki A (2010) Immunomodulatory beta-cell, and neuroprotective actions of fenugreek oil from alloxaninduced diabetes. Immunopharmacol Immunotoxicol 32: 437-445. Link: https://bit.ly/3Am55s0

20. Uemura T, Hirai S, Mizoguchi N, Goto T, Lee JY, et al. (2010) Diosgenin present in fenugreek improves glucose metabolism by promoting adipocyte differentiation and inhibiting inflammation in adipose tissues. Mol Nutr Food Res 54: 1596-1608. Link: https://bit.ly/3AguBPs

21. Xue W, Lei J, Li X, Zhang R (2011) Trigonella foenum graecum seed extract protects kidney function and morphology in diabetic rats via its antioxidant activity. Nutr Res 31: 555-562. Link: https://bit.ly/37r5T2m

22. Puri D, Prabhu KM, Murthy PS (2012) Antidiabetic Effect of GII Compound Purified from Fenugreek (Trigonella foenum graecum Linn) Seeds in Diabetic Rabbits. Indian J Clin Biochem 27: 21-27. Link: https://bit.ly/2VBG7Go

23. Hamza N, Berke B, Cheze C, Le Garrec R, Umar A, et al. (2012) Preventive and curative effect of Trigonella foenum-graecum L. seeds in C57BL/6J models of type 2 diabetes induced by high-fat diet. J Ethnopharmacol 142: 516-522. Link: https://bit.ly/3iztdl3

24. Gupta SK, Kumar B, Nag TC, Srinivasan BP, Srivastava S, et al. (2014) Effects of Trigonella foenum-graecum (L.) on retinal oxidative stress, and proinflammatory and angiogenic molecular biomarkers in streptozotocininduced diabetic rats. Mol Cell Biochem 388: 1-9. Link: https://bit.ly/3Aol6MT

25. Neelakantan N, Narayanan M, de Souza RJ, van Dam RM (2014) Effect of fenugreek (Trigonella foenum-graecum L.) intake on glycemia: a metaanalysis of clinical trials. Nutr J 13: 7. Link: https://bit.ly/2VGU5pX

26. Smith JD, Clinard VB (2003) Natural products for the management of type 2 diabetes mellitus and comorbid conditions. J Am Pharm Assoc 54: e304-e318. Link: https://bit.ly/3IKIWQ7

27. Rawat AK, Korthikunta V, Gautam S, Pal S, Tadigoppula N, et al. (2014) 4-Hydroxyisoleucine improves insulin resistance by promoting mitochondrial biogenesis and act through AMPK and Akt dependent pathway. Fitoterapia 99 307-317. Link: https://bit.ly/3iwk2le

28. Gaddam A, Galla C, Thummisetti S, Marikanty RK, Palanisamy UD, et al. (2015) Role of Fenugreek in the prevention of type 2 diabetes mellitus in prediabetes. J Diabetes Metab Disord 14: 74. Link: https://bit.ly/3fJYJed

29. Verma N, Usman K, Patel N, Dhakre S, Jain A, et al. (2016) A multicenter clinical study to determine the efficacy of a novel fenugreek seed (Trigonella foenum-graecum) extract (Fenfuro ${ }^{\mathrm{TM}}$ ) in patients with type 2 diabetes. Food Nutr Res 60: 32382. Link: https://bit.ly/3xsqga9

30. Geberemeskel GA, Debebe YG, Nguse NA (2019) Antidiabetic Effect of Fenugreek Seed Powder Solution (Trigonella foenum-graecum L.) on Hyperlipidemia in Diabetic Patients. J Diabetes Res 2019: 8507453. Link: https://bit.ly/3jvh8wo

31. Hadi A, Arab A, Hajianfar H, Talaei B, Miraghajani M, et al. (2020) The effect of fenugreek seed supplementation on serum irisin levels, blood pressure, and liver and kidney function in patients with type 2 diabetes mellitus: A parallel randomized clinical trial. Complement Ther Med 49: 102315. Link: https://bit.ly/3s2DZmG

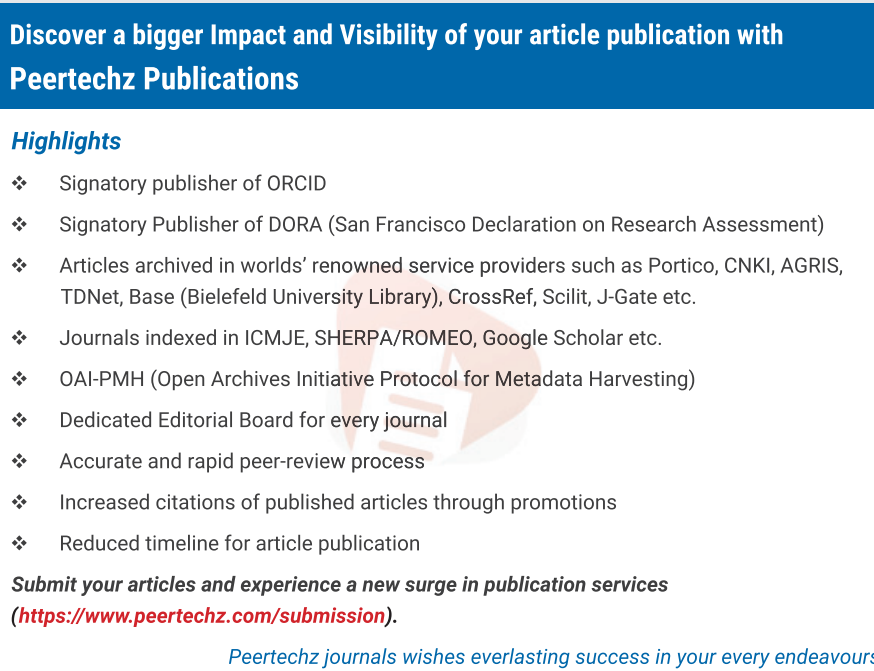

Copyright: @ 2021 Al Mosawi AJ. This is an open-access article distributed under the terms of the Creative Commons Attribution License, which permits unrestricted use distribution, and reproduction in any medium, provided the original author and source are credited. 